\title{
A Review on the Study of Strength Properties of High Performance Concrete Using Various Fibers
}

\author{
S. Venkateshwaran ${ }^{1}$, A. Alex Rajesh ${ }^{2 *}$ \\ ${ }^{1}$ PG Student, Department of Civil Engineering, KSR College of Engineering, Tiruchengode, Tamil Nadu, India. \\ ${ }^{2}$ Assistant Professor, Department of Civil Engineering,KSR College of Engineering, Tiruchengode, Tamil Nadu, \\ India \\ *Corresponding author E-Mail ID: alexrajksr@gmail.com
}

Doi: https://doi.org/10.34256/irjmtcon56

\begin{abstract}
This is review report on High performance Concrete and is done by studying various journal papers on High performance concrete and this paper mainly concentrated on how to improve the Strength of concrete by using various fibers. Fibers are generally used in concrete to improve the tensile strength of the concrete. In fiber Reinforced Concrete (FRC) various types of fibers can be used such as polypropylene, cellulose, carbon, jute, PET fibers and Steel fibers. Among the above all steel fibers shows best performance comparing to other fibers. The flexural strength and compressive strength test are commonly done for every fiber and their values and comparisons are discussed in this report.
\end{abstract}

Keywords: FRC, SFSC, SFRC, GFRC, PFRC, Admixture

\section{INTRODUCTION}

Admixtures are used in concrete since 1900 for imparting various properties to the concrete. Nowadays over usage of certain ingredients in concrete also increased the need of alternatives. Concrete is the most abundant material used in the construction process. Normally plain concrete possess low tensile strength, little resistance to cracking and poor ductility. Literally to improve the tensile strength of the PCC (plain cement concrete), steel bars are provided (ie.RCC). The Fiber Reinforced Concrete (FRC) is the solution to quench the thirst of new era of concreting. There are various types of fibers used such as steel fibers (hooked end, flat steel, and waving steel fibers), glass fibers, polymers etc. The FRC exhibits high tensile strength and more resistant to fire comparing to conventional concrete. In Glass fiber reinforced concrete (GFRC) the glass fibers with short length are dispersed in cementitious matrix composed of cement, sand, coarse aggregate, water, polymer and admixtures. Whereas in Steel fiber reinforced concrete (SFRC) the discrete steel fibers discontinuously made with the hydraulic cement with fine and coarse aggregate. The comparative study of various FRC is done in this project.

\section{II.TYPES OF FIBERS DISCUSSED}

\section{Steel Fibers}

Steel fiber is a metal reinforcement they are used for reinforcing concrete in short discrete lengths with an aspect ratio from about 20-100. 


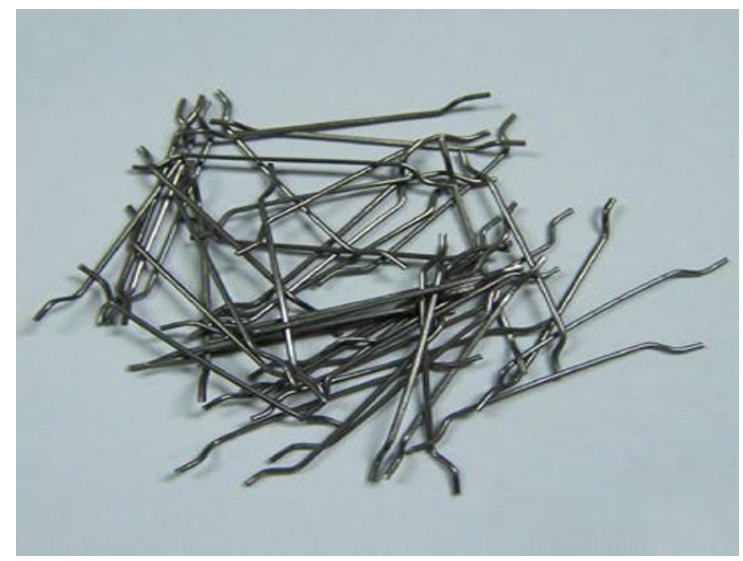

Fig 1.1 Steel Fibers

\section{Glass Fibers}

Fiber glasses simply very fine glass fibers. Alkali resistant (AR Glass Fiber, Glass Fibers are designed specifically for use in concrete. They are manufactured from a specially formulated glass composition within optimum level of zirconia.AR Glass fibers are high tensile strength and modulus, do not rust like steel and are easily incorporated into concrete mixes.

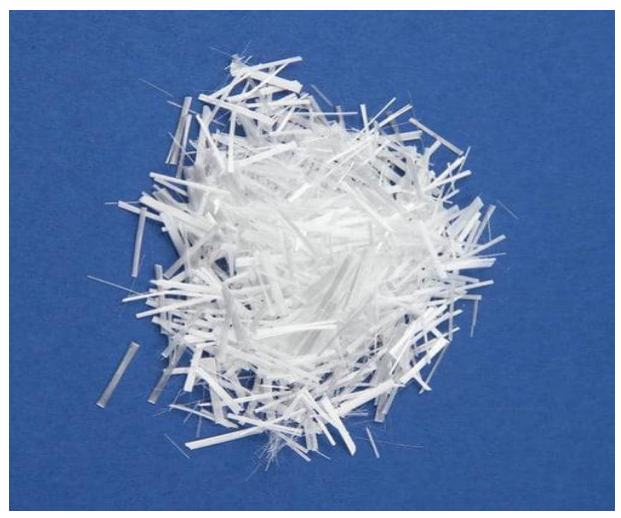

Fig 1.2 Glass fibers

\section{Polymer Fibers}

Some of the synthetic fibers used in concrete are nylon, polyether, polypropylene and polyethylene. It improves stiffness and impact stress.

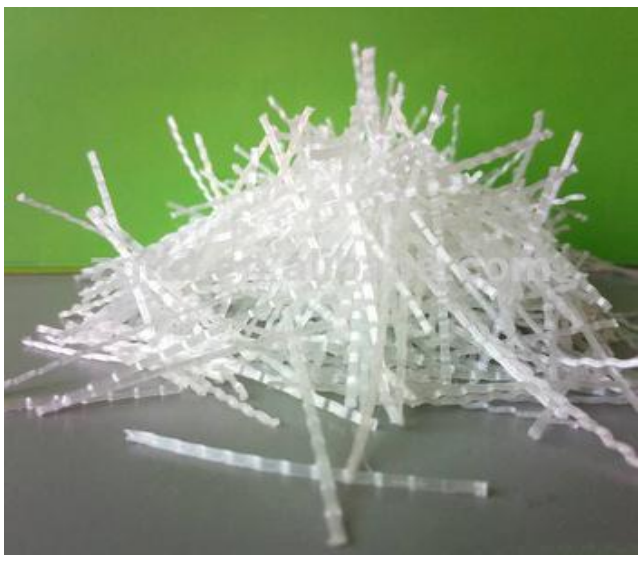

Fig 1.3 Polymer Fibers 


\section{RELATED WORK}

Milind V et al., (2012) Reinforced Concrete (SFRC) is its superior resistance to cracking and crack propagation. In this paper effect of fibers on the strength of concrete for M 30 grade have been studied by varying the percentage of fibers in concrete. Fiber content were varied by $0.25 \%, 0.50 \%, 0.75 \%, 1 \%, 1.5 \%$ and $2 \%$ by volume of cement. Cubes of size $150 \mathrm{mmX} 150 \mathrm{mmX} 150 \mathrm{~mm}$ to check the compressive strength and beams of size $500 \mathrm{mmX} 100 \mathrm{mmX} 100 \mathrm{~mm}$ for checking flexural strength were casted. All the specimens were cured for the period of 3, 7 and 28 days before crushing. The results of fiber reinforced concrete for 3days, 7days and 28days curing with varied percentage of fiber were studied and it has been found that there is significant strength improvement in steel fiber reinforced concrete. The optimum fiber content while studying the compressive strength of cube is found to be $1 \%$ and $0.75 \%$ for flexural strength of the beam. Also, it has been observed that with the increase in fiber content up to the optimum value increases the strength of concrete. Slump cone test was adopted to measure the workability of concrete. The Slump cone test results revealed that workability gets reduced with the increase in fiber content.[9]

A.M. Shende et al., (2012) Critical investigation for M-40 grade of concrete having mix proportion 1:1.43:3.04 with water cement ratio 0.35 to study the compressive strength, flexural strength, Split tensile strength of steel fibre reinforced concrete (SFRC) containing fibers of 0\%, $1 \%, 2 \%$ and 3\% volume fraction of hook tain. Steel fibers of 50, 60 and 67 aspect ratio were used. A result data obtained has been analyzed and compared with a control specimen ( $0 \%$ fiber). A relationship between aspect ratio vs. Compressive strength, aspect ratio vs. flexural strength, aspect ratio vs. Split tensile strength represented graphically. Result data clearly shows percentage increase in 28 days Compressive strength, Flexural strength and Split Tensile strength for M-40 Grade of Concrete.[6]

AmitRai et al., (2014) Fibre reinforced concrete (FRC) is cementing concrete reinforced mixture with more or less randomly distributed small fibres. In the FRC, a numbers of small fibres are dispersed and distributed randomly in the concrete at the time of mixing, and thus improve concrete properties in all directions. The fibers help to transfer load to the internal micro cracks. FRC is cement based composite material that has been developed in recent years. It has been successfully used in construction with its excellent flexural-tensile strength, resistance to spitting, impact resistance and excellent permeability and frost resistance. It is an effective way to increase toughness, shock resistance and resistance to plastic shrinkage cracking of the mortar. These fibers have many benefits. Steel fibers can improve the structural strength to reduce in the heavy steel reinforcement requirement.[10]

RamuPalankar et al., (2014) PFRC can be used advantageously over normal concrete pavement. Polymeric fibers such as polyester or polypropylene are being used due to their cost effective as well as corrosion resistance. PFRC requires specific design considerations and construction procedures to obtain optimum performance. The higher initial cost by $15-20 \%$ is counterbalanced by the reduction in maintenance and rehabilitation operations, making PFRC cheaper than flexible pavement by 30-35\%. In a fast developing and vast country like India, road networks ensure mobility of resources, communication and in turn contribute to growth and development.[11]

Abdul Ghaffar et al., (2014) The purpose of this research is based on the investigation of the use of steel fibres in structural concrete to enhance the mechanical properties of concrete. The objective of the study was to determine and compare the differences in properties of concrete containing without fibres and concrete with fibres. This investigation was carried out using several tests, compressive test and flexural test. A total of eleven mix batches of concrete containing $0 \%$ to $5 \%$ with an interval of $0.5 \%$ by wt. of cement. 'Hooked' steel fibres were tested 
to determine the enhancement of mechanical properties of concrete. The workability of concrete significantly reduced as the fibre dosage rate increases.[5]

FazlurRehman et al., (2015) The present study alkali resistant glass fibres were used in the concrete mixes. A total of 8 mixes were prepared by varying the percentages of glass fibres and grade of concrete mixes. Based on the laboratory results the compressive and tensile strength was reported to increase up to $26.19 \%$ and $25.4 \%$. However the workability of concrete mixes is not much affected by the addition of fibres. The tensile strength of concrete is improved which shows the use of glass fibres in concrete mixes may reduce its shortcoming of low tensile strength without affecting its workability and compressive strength.[2]

J. D. Chaitanya Kumar et al., (2016) The present trend in concrete technology is towards increasing the strength and durability of concrete to meet the demands of the modern construction. The main aim of the study is to study the effect of glass fibre and steel fibers in the concrete. FRC has the high tensile strength and fire resistant properties thus reducing the loss of damage during fire accidents. In the present work the strength studies are carried out to compare the glass and steel fiber concrete. The FRC is added 0.5, 1, 2 and 3\% are added for M20 grade concrete. Result shows the percentage increase in compressive strength, flexural strength and split tensile strength for 28days.[1]

IshanGarg et al., (2016) Mainly the studies and research in fiber reinforced concrete has been devoted to steel fibers. In recent times, glass fibers have also become available, which are free from corrosion problem associated with steel fibers. The present paper outlines the experimental investigation conducts on the use of glass fibers with structural concrete. CEM-FILL anti crack, high dispersion, alkali resistance glass fiber of diameter 14 micron, having an aspect ratio 857 was employed in percentages, varying from 0.33 to 1 percentage by weight in concrete and the properties of this FRC (fiber reinforced concrete) like compressive strength, flexure strength, toughness, modulus of elasticity were studied.[3]

S.Hemalatha et al., (2016) The study work is focused on strength and durability characteristics of GFRC. As per IS 10262-2009 designed by M40 grade of Concrete and con plast as a super plasticizer and water cement ratio 0.40. The performance of Cement Concrete with varying percentage of Glass Fibre adding like $0.33 \%, 0.66 \%, 1 \%, 1.33 \%, 1.66 \%, 2 \%$. The strength and durability properties of Glass Fibre Reinforced Concrete compared to Control Concrete [4]

Rubén Serrano et al., (2016), The decrease in concrete resistance and the expansion generated in reinforced concrete structures by direct exposure to fire at $400 \mathrm{C}$ maximum temperatures serves as the basis for the present research. The aim is to improve these problems by the addition of steel fibers or of polypropylene fibers in concrete. From the results analysis of compression fracture tests on cylindrical concrete specimens, it can be concluded that concrete with addition of polypropylene fibers or steel fibers are a good alternative to traditional concrete, because both its strength, and its behavior in case of fire are improved, delaying the appearance of fissures and explosive concrete spalling.[8]

PramodKawde et al., (2017) In this project Steel Fiber reinforced concrete (SFRC) is defined as concrete made with hydraulic cement containing Fine and coarse aggregate and discontinuous discrete fiber. In SFRC, thousands of small fibers are dispersed and distributed randomly in the concrete during mixing, and thus improve concrete properties. SFRC is being increasingly used to improve static and dynamic tensile strength, energy absorbing capacity and better fatigue. They concluded that the addition of steel fiber increases the ultimate strength and ductility. The plain structure cracks into two pieces when the structure is subjected to the peak tensile load and cannot withstand further load or deformation.[7] 


\section{CONCLUSION}

From the above all investigation it has been concluded at steel fiberprovide high tensile strength then the other fibers. Where Glass fibers are provide resistance through rust. The polypropylene fiber reduced early age shrinkage when low volume fractions of the fibers are gives. However the addition of the above fibers will increase the cost of conception.

\section{REFERENCES}

1. A.M. Shende, A.M. Pande, M. GulfamPathan,\&quot; “Experimental Study on Steel Fiber Reinforced Concrete for M-40 Grade\&quot”, International Refereed Journal of Engineering and Science (IRJES), Vol. 1, 2012.

2. Milind V. Mohod,\&quot; "Performance of Steel Fiber Reinforced Concrete\&quot;, International Journal of Engineering and Science", Vol. 1, Pp. 1-4, 2012.

3. Abdul Ghaffar, Amit S. Chavhan, Dr.R.S.Tatwawadi,\&quot; "Steel Fibre Reinforced Concrete\&quot;, International Journal of Engineering Trends and Technology" (IJETT), Vol. 9, 2014.

4. AmitRai and Dr. Y. P. Joshi, "Applications and Properties of Fibre Reinforced Concrete”, Int. Journal of Engineering Research and Applications", ISSN: 2248-9622, Vol. 4, Issue 5 ( Version 1), May 2014.

5. S.A Kanalli, RamuPalankar, Bharath Kumar, Praveen Kumar,Prakash S.K, "Comparative Study Of Polymer Fibre Reinforced Concrete With Conventional Concrete Pavement'International Journal of Research in Engineering and Technology, Volume: 03 Issue: 01 | Jan-2014.

6. Md.AbidAlam, Imran Ahmad, FazlurRehman, "Experimental Study on Properties of Glass Fibre Reinforced Concrete" International Journal of Engineering Trends and Technology (IJETT) - Volume 24 Number 6- June 2015.

7. E. Arunakanthi, J.D. Chaitanya Kumar, "Experimental Studies OnFiber ReinforcedConcrete (FRC)"'International Journal of Civil Engineering and Technology (IJCIET) Volume 7, Issue 5, September-October 2016.

8. GuarvThuli, IshanGarg, "Study Of Glass Fibre Reinforced Concrete" IOSR Journal of Mechanical and Civil Engineering (IOSR-JMCE), Volume 13, Issue 3 Ver. VI (May- Jun. 2016).

9. S. Hemalatha, Dr. A. Leema Rose, "An Experimental Study Of Glass Fibre Reinforced Concrete"International Research Journal of Engineering and Technology (IRJET), Volume: 03 Issue: 04 | April-2016.

10. Rubén Serrano, Alfonso Cobo, María Isabel Prieto and María de las Nieves González,\&quot; "Analysis of fire resistance of concrete with polypropylene or steel fibers\& quo"; Construction and Building Materials, Vol.122, Pp. 302-309, 2016.

11. PramodKawde,AbhijitWarudkar, "Steel Fibre Reinforced Concrete A Review" International Journey of Engineering Science And Research Technology, January, 2017. 